\title{
Towards a global policy against alcohol marketing to youth: Challenges and recommendations for research
}

\author{
Alisa Padon, ${ }^{1}$ Rajiv N. Rimal ${ }^{2}$ \\ ${ }^{1}$ The Public Health Institute, Oakland, CA; ${ }^{2}$ The George Washington University, Washington, DC, USA
}

\section{Background}

A significant body of work now indicates that adult onset of alcoholism and alcohol-related problems can be traced back to underage drinking. ${ }^{1,2}$ Despite numerous countries' efforts to curtail underage drinking, it remains a significant global public health issue, ${ }^{3,4}$ and alcohol marketing has been identified as one of the primary contributors to this growing problem. ${ }^{5}$

Among various tools countries can use to curtail underage drinking, an important one is formulating and implementing policies that govern alcohol marketing practices, especially those directed toward children and adolescents. Developing such policies, however, must be based on sound scientific evidence, which could come in at least two forms: demonstration of impact of drinking and a marketing causal vector that links advertising with underage consumption of alcohol. By impact, we mean that the evidence needs to point to the effects of underage drinking. It would show the deleterious effects not only on individuals themselves, but also on their social networks, communities, and society as a whole, thus compelling the need for change. Second, the evidence needs to demonstrate a marketing causal vector, ability to make a causal link between the marketing or advertisement of alcohol, either directly or indirectly, to youth, on the one hand, with subsequent underage consumption of alcohol, on the other.

A substantial body of work demonstrates both these aspects. ${ }^{5-8}$ A number of countries have sound policies in place restricting the direct marketing of alcohol to children and adolescents and/or imposing stringent restrictions on alcohol marketing to which youth are indirectly exposed; a comprehensive list is compiled in the Global Health Observatory data repository. ${ }^{9}$ Globally, however, much more needs to be done, including in amassing evidence about the effectiveness of such policies in curtailing underage alcohol consumption. Are such policies effective and what challenges must the scientific community face to contribute to that literature? These are some of the questions we raise in this editorial. We frame our discussion around challenges along two pillars: enacting effective marketing policies and evaluating the effectiveness of such policies in curtailing underage advertising exposure.

\section{Challenges in passing effective marketing policies}

Passing effective marketing policies is dependent, to a large extent, on the surrounding political context. Environments like those in the United States have less restrictions due to the First Amendment of the US constitution. The commercial speech of the alcohol industry is protected under the law, and attempts to regulate alcohol advertising must pass strict scrutiny. Many countries have opted for a quasi-regulatory or industry self-regulatory schemes. However, many public health agencies are rightfully concerned that a self-regulatory system does not adequately protect youth from exposure to alcohol advertising. ${ }^{10}$ In most countries, restricting speech through government regulation, the recommendation of the World Health Organization, ${ }^{10}$ is legal when a compelling health case can be made. In these countries, a total ban on advertising, such as in Turkey, ${ }^{11}$ would be the most effective, and the easiest and least expensive to implement, but the measure would likely face significant industry opposition. ${ }^{12}$ Many countries have no current regulation at all (WHO, 2010), and in these contexts, marketers are given free reign.

As an alternative to regulation in countries with protected speech, the industry may be compelled to speak, via health and safety warning labels. In the U.S., warnings may be required as long as the text and any graphics used convey factual and uncontroversial information, and as long as the posting requirements are not overly burdensome. ${ }^{13}$ However, what is factual and uncontroversial is not always apparent, as the ruling on graphic warning labels on tobacco cigarette packs illustrated. ${ }^{14}$

\section{Challenges in evaluating policy effectiveness in curtailing underage marketing exposure}

In countries without a total ban on alcohol marketing, an effective policy would result in marketing exposure exclusively on adults, shielding youth from the industry's marketing efforts. Yet there is considerable evidence that youth are exposed to an inordinate amount of marketing. ${ }^{5}$ Researchers wishing to document the effectiveness of such policies face a number of challenges, one of which is to document and quantify youth exposure to marketing, thus creating an evidence base. One way to operationalize this is to categorize youth exposure into two groups those pertaining to the production of the marketing efforts and those pertaining to their receipt by youth, what in the industry is called the supply side and the demand side, respectively.

Creating the evidence base on the supply side requires accounting for local, regional, and national marketing efforts across a variety of channels, from point-of-sale advertising to sponsorship of local events to advertising in mass media. These data are often difficult to obtain because of the proprietary nature of the industry efforts. Furthermore, with digital advertising, much of the industry effort can also take place under the radar, with direct-to-youth messaging. Without compelling the industry to disclose its total marketing expenditure and information about marketing venues and revenues, researchers are often left with incomplete information about the volume of marketing that is directed toward youth.

On the demand side, exposure is often assessed through content analyses of media products (e.g., television shows, maga- 
zines, etc.) that carry alcohol advertising and self-reports about exposure to them. Using this method, however, often results in underestimation of youth exposure, not only because it is difficult to develop a comprehensive list of all venues, but also because youth recall can be subject to significant biases. Even if we were able to obtain an accurate listing, significant challenges remain in standardizing exposure measures in order to create a common metric that can be used by researchers.

\section{Using the evidence base}

To use evidence regarding the effects of alcohol marketing on underage consumption to inform policy, researchers must consider the regulatory environment where the marketing is taking place. The industry self-regulations in the U.S. include measures to reduce underage exposure, such as restricting advertising to media where $71.6 \%$ of the audience is of legal drinking age. ${ }^{15}$ Research relevant to this regulatory scheme is needed to evaluate whether the policy is faithfully implemented and whether it is enough to protect youth from overexposure to alcohol advertising. Studies have found that much of the televised alcohol advertising in the U.S. appears in media with audiences disproportionately consisting of youth. ${ }^{16,17}$ Researchers have thus recommended that the threshold of youth audience should be lowered from $28.4 \%$ to $15 \%$ (roughly the proportion of 12-20 year olds in the population) ${ }^{18}$ and that advertisers should use local, rather than national, audience composition data to avoid violating the audience threshold rule. ${ }^{19}$

The industry also self-limits the content it uses in marketing, stipulating that advertisements cannot primarily appeal to youth, ${ }^{15}$ but the guidelines do not clearly define primarily youth appealing content. ${ }^{20}$ In this regard, some of our team's work has used existing literature to create a metric, the Content Appealing to Youth (CAY) index, that captures media content appealing to youth. ${ }^{21}$ Subsequent research has shown that CAY content is positively associated with brand-specific youth consumption, but not with adult consumption. ${ }^{21}$ More work needs to be done, however, to validate this index across different settings and contexts.

In voluntary self-regulation schemes there is often no governmental avenue by which to use evidence to change marketing practices, but effective dissemination and advocacy can put pressure on the industry to revise its guidelines. In this regard, research can be supportive of health and safety warning labels by focusing on the scientific accuracy of the label language and on the link between exposure to warning labels and impact on key outcomes like underage consumption.

In a context where more restrictive regulation is allowed (as in Finland), evidence that $68 \%$ of the country's 15 and 16 year olds had used alcohol can be politically powerful. ${ }^{3}$ The 2014 update to the Alcohol Act (Ministry of Social Affairs and Health, Finland, 2014) restricted placement of advertising to avoid youth exposure and advertisement content to avoid positive associations with alcohol. ${ }^{22}$

Policy change occurs when research, public health and public interest coalitions, corporate relationships, community voices, media support, and electoral and political context converge. Bringing these parties together remains a challenge in curtailing alcohol marketing. Research needs to show not only the problem, but also how the solution can be politically beneficial to a policy maker, such as how many lives it will save, how feasible it is to implement, where else the policy has been implemented, and how successful it has been. Research should also focus on rebutting the industry's counterarguments, some of which are that an $85 \%$ audience threshold would substantially affect the industry's ability to target adults, ${ }^{18}$ or that advertising is not associated with youth drinking over and above close adult or peer influence. ${ }^{23}$

\section{Looking ahead}

As far as we can tell, alcohol marketing will not suffer the same fate as tobacco marketing (for which there is a comprehensive ban in many countries). Neither are we advocating for such a policy. We are, however, advocating for a complete ban on youthfocused alcohol advertising and a ban on advertising in media whose audience members comprise $15 \%$ or more youth. Until that goal is achieved, it is incumbent upon researchers to continue to document: i) youth exposure to alcohol advertising, whether intentional or not; ii) successes and failures of municipalities, regions, and national governments to enact such policies, and iii) the link between marketing and youth alcohol consumption. In this editorial, we have highlighted some of the underlying challenges the research community faces in doing so. But this community needs support - internally, in reaching consensus on underlying methods and challenges, and externally in the form of resources so that this important work can continue.

Correspondence: Rajiv N. Rimal, Department of Prevention and Community Health, The George Washington University, 950 New Hampshire Avenue, Washington, DC 20052, USA.

Tel.: + 1.202.994.3570.

E-mail: rrimal@gwu.edu

Key words: alcoholism; youth; alcohol marketing.

Contributions: the authors contributed equally.

Conflict of interest: the authors declare no potential conflict of interest.

Received for publication: 17 October 2017.

Accepted for publication: 17 October 2017.

(C) Copyright A. Padon and R.N. Rimal, 2017

Licensee PAGEPress, Italy

Journal of Public Health Research 2017;6:1268

doi:10.4081/jphr.2017.1268

This work is licensed under a Creative Commons Attribution NonCommercial 4.0 License (CC BY-NC 4.0).

\section{References}

1. Hingson R, Heeren T, Jamanka A, Howland J. Age of drinking onset and unintentional injury involvement after drinking. JAMA 2000;284:1527-33.

2. Swahn MH, Bossarte RM, Sullivent EE. Age of alcohol use initiation, suicidal behavior, and peer and dating violence victimization and perpetration among high-risk, seventh-grade adolescents. Pediatrics 2008;121:297-305.

3. OECD. Tackling harmful alcohol use: economics and public health policy. OECD Publishing. 2015. Available from: http://www.keepeek.com/Digital-Asset-Management/oecd/ social-issues-migration-health/tackling-harmful-alcoholuse_9789264181069-en

4. Paschall MJ, Grube JW, Kypri K. Alcohol control policies and alcohol consumption by youth: a multi-national study. Addiction 2009; 104:1849-55.

5. Smith LA, Foxcroft DR. The effect of alcohol advertising, marketing and portrayal on drinking behaviour in young people: systematic review of prospective cohort studies. BMC Public Health 2009;9:51. 
6. Anderson P, de Bruijn A, Angus K, et al. Impact of alcohol advertising and media exposure on adolescent alcohol use: a systematic review of longitudinal studies. Alcohol Alcohol 2009;44:229-43.

7. Snyder LB, Milici FF, Slater M, et al. Effects of alcohol advertising exposure on drinking among youth. Arch Pediatr Adolesc Med 2006;160:18-24.

8. Stacy AW, Zogg JB, Unger JB, Dent CW. Exposure to televised alcohol ads and subsequent adolescent alcohol use. Am J Health Behav 2004;28:498-509.

9. World Health Organization. Global Health Observatory data repository. Advertising restrictions. Available from: http://apps.who.int/gho/data/node.main.A1131?lang=en. Accessed on: September 2017.

10. World Health Organization. Global strategy to reduce harmful use of alcohol. 2010. Available from: http://www.who.int/substance_abuse/activities/gsrhua/en/

11. European Centre for Monitoring Alcohol Marketing. Turkey. 2017. Available from: http://eucam.info/regulations-on-alcohol-marketing/turkey/. Accessed on: September 2017.

12. Nichols J. Global context of alcohol policy. In Kolind T, Thom B, Hunt G, Eds. SAGE handbook of drug and alcohol studies: social science approaches. Thousand Oaks: SAGE Publications, Inc.; 2017.

13. Zauderer v. Office of Disciplinary Counsel of the Supreme Court of Ohio: States' Rights v. The First Amendmen. Am. Bev. Assn. v. San Francisco, F.3d US (Ninth Circuit 2017).

14. R.J. Reynolds Tobacco Co. v. U.S. Food \& Drug Administration. 696 F.3d 1205 (D.C. Cir. 2012).

15. Federal Trade Commission. Self-regulation in the alcohol industry: report of the Federal Trade Commission. 2014. Available from: https://www.ftc.gov/reports/self-regulation- alcohol-industry-report-federal-trade-commission-0

16. Jones SC, Donovan RJ. Self-regulation of alcohol advertising: is it working for Australia? J Public Aff 2002;2:153-65.

17. Ross CS, Brewer RD, Jernigan DH. The potential impact of a "no-buy" list on youth exposure to alcohol advertising on cable television. J Stud Alcohol Drugs 2016;77:7-16.

18. Bonnie RJ, O'Connell ME, National Research Council, Institute of Medicine, Committee on Developing a Strategy to Reduce and Prevent Underage Drinking. Reducing underage drinking: a collective responsibility. Washington DC: National Academies Press US; 2004.

19. Centers for Disease Control and Prevention. Morbidity and Mortality Weekly Report. Youth exposure to alcohol advertising on television — 25 Markets, United States, 2010. 8 November 2013. Available from: https://www.cdc.gov/mmwr/preview/mmwrhtml/mm6244a3.h tm

20. Babor TF, Xuan Z, Damon D. Changes in the self-regulation guidelines of the US Beer Code reduce the number of content violations reported in TV advertisements. J Public Aff 2010;10:6-18.

21. Padon AA, Rimal RN, Jernigan DH. Linking alcohol advertising and underage drinking: triangulation of data from content analysis, youth survey, and market exposure data. New Orleans: American Public Health Association Annual Conference; 2014.

22. Ministry of Social Affairs and Health, Finland. The Alcohol Act, No. 1143/1994. Issued in Helsinki on 8 December 1994.

23. Grenard JL, Dent CW, Stacy AW. Exposure to alcohol advertisements and teenage alcohol-related problems. Pediatrics 2013;131:e369-79. 